\title{
Lunacy in the Stoke-upon-Trent workhouse 1834-1900
}

\author{
Edward Myers
}

\begin{abstract}
The Now Poor Law Amendment Act of 1834 led to the admisetion of considerable numbers of pauper "Iunatics, Idiots and imbeciles" to parish workhouses. The Stokeupon-Trent workhouse, erected in 1832, had progressively to increase its accommodation for this class of inmate who, by 1899, numbered about 100. Britef detalls are oiven of nursing staff and of improvements in conditions of care following recommendations of the Lunacy Commisstoners. Primary sources of information are indicated and emphasts is laid on the importance for the history of Engllsh poychiatiy of documenting the care of the mentally ill and mentally impaired in Union workhouses.
\end{abstract}

Under the New Poor Law Amendment Act of 1834, outdoor relief, which had been available since Elizabethan times, was no longer to be paid to the able-bodied poor who, if they could not subsist in the community, had to be admitted to the parish workhouse. Although the legislation made little specific mention of pauper lunatics other than that "no dangerous Lunatic, insane Person, or Idiot" was to be kept for longer than 14 days in any workhouse, by 1885 , of 79,704 persons officially identified as insane (Scull, 1979), 17,282 (21.6\%) were in workhouses (Commissioners in Lunacy, 1885).

Documentation of how the insane and mentally impaired inmates fared is sparse. Detailed clinical records of sick inmates of workhouses were not kept until the 1920s and the principal primary sources of information about the conditions of care are the voluminous files of correspondence between the Poor Law Board (renamed, in 1871, Local Government Board) in London and local Boards of Guardians, and the minutes of the meetings of the latter. Within the pages of these are to be found details of the accommodation provided specifically for pauper lunatics and imbeciles and the controversies surrounding such provision, particulars of staff, reports of the Lunacy Commissioners and Poor Law Inspectors following visits to the workhouse and the 'Annual Return of Lunatics' which the clerk of the Union was required to furnish to the central authority.

The Stoke-upon-Trent workhouse was erected in 1832 and, from the outset, was intended to be

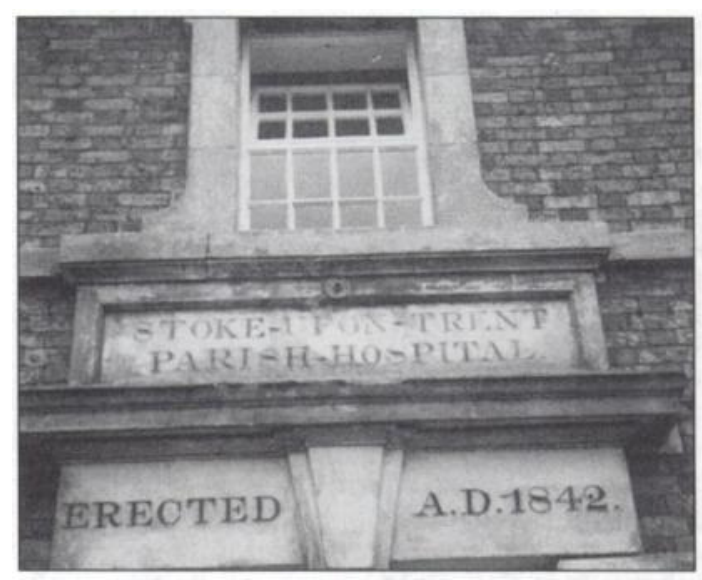

Notice above entry to original Stoke-on-Trent workhouse hospital, erected 1842. The building is now used to house the Biomedical Engineering and Physiotherapy Departments of the City General Hospital.

"an asylum to the infirm poor who are unable to work; to the orphans who have no protection; to the destitute who have no refuge; and to the aged who are friendless" (Baker, 1954). It was not until ten years later that it became evident, as it did throughout the country, that the infirm poor and many of the destitute and aged required different accommodation and conditions of care from that of the standard workhouse regime. A basic principle of the workhouse system was the deterrence of the able-bodied poor from seeking relief by $a$ harsh and unattractive regime - something quite inappropriate to the needs of those who had been driven to seek admission by virtue of physical or mental infirmity. Proposals for separate accommodation for the latter in the Stoke workhouse were first put forward by a special committee of the Board of Guardians in 1842 and included "male and female lunatic wards". Eight-inch iron bars were to be fitted to the windows of the latter and eight double bedsteads (why double?) were to be provided for the "Idiots" Sleeping Rooms". 


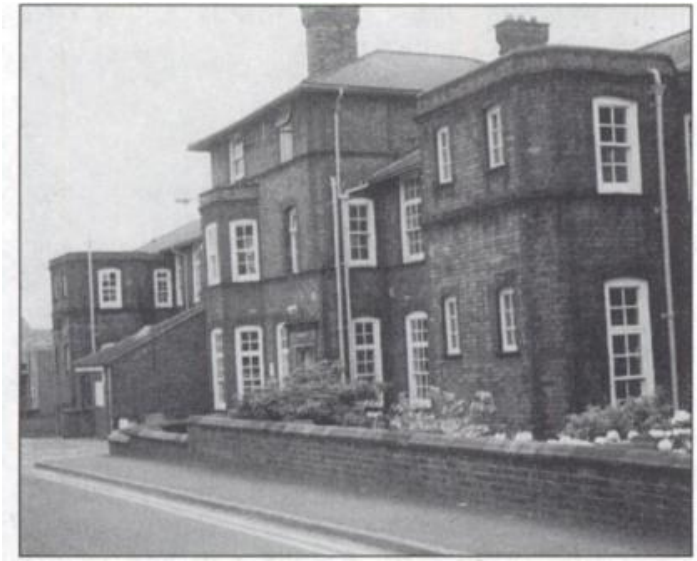

Workhouse female lunatic wards. Erected 1894. Still in use as part of Stoke-on-Trent Clity General Hospltal Psychiatric Unit.

There is no indication that the plan to provide separate accommodation for lunatics was implemented until 1866 when, with the erection of a new school, the existing school was converted, at a cost of about $\$ 500$, to accommodation for 44 pauper lunatics. This, too, proved inadequate, and under pressure from the Local Government Board, the Guardians of the Stoke workhouse (which had now, to reduce stigma, been renamed London Road Institution) agreed to build a new hospital of 150 beds and to use the existing hospital for the male old and infirm with space for male lunatics and imbeciles, the female lunatics and imbeciles to remain accommodated in the old school.

By 1885 there was accommodation for 45 male and 43 female lunatics but the Lunacy Commissioners were concerned that, because of overcrowding in the rest of the workhouse, other patients were being accommodated in the lunacy wards. They complained to the Guardians that "cases of slight epilepsy not affecting the mind and of old people who are childish and for whom there is no other ward in the workhouse" were being accommodated in the lunacy wards. These wards, they maintained, should be reserved for certified inmates. The outcome of this was an agreement in 1891 to erect, at a cost of $\$ 11,340$. two new wards specifically for lunatics (Stokeupon-Trent Poor Law Union Minutes, 1892). These wards came into operation in 1894 and, over the subsequent 100 years, have provided the population of North Staffordshire with a psychiatric facility associated with a general hospital.

Special lunacy attendants were first appointed in the 1870s when the lunatics and imbeciles began to be housed separately from other sick inmates. On 31 January 1872 , Joseph Weetnam, age 38, was appointed nurse at a salary of $£ 15$ per annum plus emoluments, this being the first time that a nurse was described as a "Lunacy Attendant". His career ended ignominiously, however. On 30 November 1881 , William Wilkins, age 48, previously farm industrial trainer, was appointed Attendant upon Lunatics at a salary of £30 per annum, his appointment following the resignation of Joseph Weetnam for neglect of duty. The Guardians' minutes of 5 October 1881 reveal Weetnam's dereliction to have lain in his "practice of delegating, without supervision, the performance of important duties to a pauper attendant" with the result that several imbecile inmates had been the victims of acts of violence. It was common practice in the late 19th century, when numbers of nursing staff were few, for the paid attendants to be assisted by unpaid pauper inmates. Numbers of paid attendants increased only slowly. In the report of the Local Government Inspector for June 1882 , it is recorded that for $\mathbf{5 3}$ male and $\mathbf{5 5}$ female lunatic inmates there was a staff of four day nurses, one night nurse, and two nurses for imbeciles. By 1894 a hierarchy had developed of head lunatic attendant with a number of male and female lunatic attendants and assistant lunatic attendants under his supervision.

The first available report of a visit to the Stoke workhouse of a Lunacy Commissioner is that of 1848; it lists the "number of inmates of unsound mind" as eight (one male and seven females). The numbers increase progressively over the years, being 18 (seven males and 11 female) in 1866, 37 ( 18 male and 19 female) in 1875, 64 ( 33 male and 31 female) in 1881, and 97 (38 male and 59 female) in 1899.

From the 1860s onwards, the Lunacy Commissioners' reports provide evidence of an increasing humanisation of the workhouse system such that only the wards for the able-bodied continued to conform to the deterrent ideology. "Some cheap prints and some illustrated papers and indoor games" are recommended in 1863 to "amuse and occupy" the inmates and "the introduction of comfortable settees" and a lookingglass in the female day-room are suggested in 1872. Books and periodicals were supplied and in 1899 the Guardians agreed to purchase a musical box for the female wards "at a cost not to exceed 15" (Lunacy Commissioners' Reports on visits to the Stoke-upon-Trent workhouse).

This brief account of lunacy in the Stoke-uponTrent workhouse from the date of introduction of the New Poor Law until the turn of the century is presented to draw attention to the sources of information available to anyone wishing to research the conditions of care of pauper lunatics in Union workhouses. Unfortunately the correspondence files post 1900 were destroyed by 


\section{THE HISTORY OF PSYCHIATRY}

enemy bombing during World War II but the minutes of meetings of Boards of Guardians up to the date of their dissolution in 1930 are generally available in public reference libraries or county record offices. The documentation of the conditions of care of lunatics, idiots and imbeciles (to use the terms appropriate to the period under consideration) in Union workhouses would appear to be a necessary supplement to the history of the asylums if the story of the care of the mentally ill and mentally impaired in England in the 19th and 20th centuries is to be fully recorded.

\section{Acknowledgements}

I am obliged for advice in the preparation of this paper to Mr John Briggs and The Horace Barks Library, Hanley, Stoke-on-Trent; the
Public Records Office, Kew kindly allowed me access to relevant documents.

\section{References}

BAKER, D. (1954) Workhouses in the Potterles, p. 15. City of Stoke-on-Trent Historical Buildings Survey.

Lunacy Commissioners' Reports on Visits to the Stoke-uponTrent Workhouse. Public Record Office, MH12, 11471. 11498.

Stoke-upon-Trent Poor Law Unton Minutes, 25, 5 October, 1892.

Scull, A. (1979) Museums of Madness, p. 224. London: Allen Lane.

39th Annual Report of the Commissioners in Lunacy (1885).

Edward Myers, Honorary Research Fellow in Psychiatry, University of Keele, Department of Psychiatry, North Staffordshire Hospital Centre, Thornburrow Drive, Hartshill, Stoke-on-Trent ST4 7QB

\section{One man's meat ...}

To my mind there is nothing quite so dramatic in all clinical psychiatry - perhaps in all clinical medicine - as the swing from mania into depression, or vice versa, of the patient suffering from true, bi-polar manic-depressive psychosis.

Bert was one such case. Then aged 70 , his life for the past 30 years had been laid waste by his chronic illness. Every recommended form of treatment had been tried with no success.

When he was 'high' he was as merry and chirpy as a cricket. There was no job, or jobs, in the ward that he wouldn't have gladly undertaken, although there was no guarantee that he would ever complete any one of them. When he plummeted down from his sunlit, affective mountain top to the dark dungeon of despair he was tragically transformed into an inert, near-mute zombie.

That was how I found him when I returned from leave. I knew that to attempt to comfort him in this phase was hopeless but I felt impelled at least to try. "What's the matter Bert?" I asked, trying to be as reassuring as I could. "I'm the wickedest man in the world," he eventually replied with a sigh like a steam engine. "It's the masturbation when I was young, that's what's done it." "But Bert," I interjected, knowing the futility of what I was about to say but was, nevertheless, fool enough to go on and say it, "Ninety five per cent, at least, of all males have at some time masturbated." His tormented features became suffused with anger and his voice took on a matching edge. "You damned doctors are all the same. You just don't understand, none of you. You don't understand why I'm different from all the other 'males', as you call them. I enjoyed it!"

Henry R. Rollin, Emeritus Consultant Psychiatrist 